\title{
Umbilical Coiling Index as a Marker of Perinatal
} Outcome

\author{
Dr. T. Shobha ${ }^{1}$, Dr. V. Sai Sharanya ${ }^{2}$ \\ ${ }^{1}$ Associate Professor Modern Government Maternity Hospital, Petlaburz, Department of Obstetrics and Gynaecology, Osmania Medical \\ College, Hyderabad - Telangana
}

${ }^{2}$ Post Graduate, Modern Government Maternity Hospital, Petlaburz, Department of Obstetrics and Gynaecology, Osmania Medical College, Hyderabad - Telangana

\begin{abstract}
Aim: To correlate the importance of patterns of umbilical coiling in terms of umbilical coiling index with various fetal parameters in a 2 year study period. Objectives: The present study is being done to compare the perinatal outcome with the abnormal coiling of umbilical cord with respect to umbilical coiling index. Materials and Methods: This was a prospective study which was carried out in the department of Obstetrics and Gynaecology, Osmania Medical College, Hyderabad, Telangana for a period of 2 years.200 patients in active labour who were admitted in labour room irrespective of their parity were selected randomly for the study. Results: The total number of cases studied were 200. The number of babies with birth weight $<2.5 \mathrm{~kg}$ are $26(13 \%)$, between $2.5-3.5 \mathrm{kgs}$ are 168(84\%) and > 3.5 are 6(3\%). Babies born with Apgar score at 1 minute < 4 were 43 (21.5\%) and > 4 were 157 (78.5\%). Babies born with Apgar score at 5 minutes < 7 were 25 (12.5\%) and > 7 were 175 (87.5\%). Out of 200 babies, 35 (17.5\%) were admitted in NICU and the rest 165(82.5\%) were not admitted. In the study of 200 babies, 23 (11.5\%) had FGR, and 177 (88.5\%) had no FGR. Out of 200 babies in the study, $52(26 \%)$ had fetal distress and the rest 148 (74\%) had no fetal distress. The meconium stained liquor was found in 42 cases (21\%) and clear liquor is seen in 158(79\%). any concentration of liquor was taken into the criteria (thin or thick). Conclusion: UCI < $10^{\text {th }}$ percentile $<0.06, \mathrm{UCI}>90^{\text {th }}$ percentile $>0.41$. The mean length of the umbilical cord in the study was $52.87+/-13.49$. The mean number of coils was $12.59+/-5.38$. The mean umbilical coiling index (UCI) was $0.24+/-0.09$ which is consistent with the previous studies. The UCI was correlated to the birth weight, APGAR score at 1 min and 5 min, NICU admissions, meconium staining, fetal distress, fetal growth restriction. HYPOCOILING (UCI $<10^{\text {th }}$ percentile) is associated with low birth weights, low APGAR score at 1 minute of the baby, low APGAR scores at 5 minutes, more NICU admissions, fetal distress associated with the baby and also meconium staining of the liquor. HYPERCOILING (UCI $>90^{\text {th }}$ percentile) is associated with low birth weights, low APGAR score at 1 minute, NICU admissions, and fetal growth restriction. It is also associated with fetal distress of the baby and also meconium staining of the liquor. Thus antenatal detection of the coiling index can identify fetus at risk and thus help in further management and timely intervention.
\end{abstract}

Keywords: Hypercoiled umbilical cord, Hypocoiled umbilical cord, Intrauterine fetal growth restriction, Meconium stained liquor, Umbilical coiling index.

\section{Introduction}

The umbilical cord or funis forms connecting link between the fetus and placenta through which the fetal blood flows to and from the placenta. . Its three blood vessels pass along the length of the cord in a coiled or helical fashion ${ }^{1}$ (spiral course $^{2}$ ). A coil is defined as completed 360 degrees spiral course of umbilical vessels around Wharton's jelly ${ }^{1}$.

- The coiling property of cord vessels was described as early as in 1521 by Berengariuls. In 1954 umbilical coiling was first quantified by Edmonds who divided the total number of coils by the umbilical cord length in centimeters and called it "the index of twist". He assigned positive and negative scores to clock wise and anti clock wise coiling respectively ${ }^{1,3}$. Later strong et al simplified by eliminating these directional scores and named it the "umbilical coiling index", 4 .

- An abnormal UCI includes both hypo coiled cords (i.e., cords with UCI $<10^{\text {th }}$ percentile) and hyper coiled cords (i.e., UCI $>90^{\text {th }}$ percentile). An abnormal umbilical coiling has been studied in relation to adverse perinatal outcomes $^{1,2,5,6,7}$.

- The present study has been undertaken to compare the perinatal outcome with the abnormal coiling of umbilical cord with respect to umbilical coiling index.

\section{Materials and Methods}

This was a prospective study which was carried out in the department of Obstetrics and Gynaecology, OSMANIA MEDICAL COLLEGE, Hyderabad, Telangana for a period of 2 years.

Ethical committee clearance was obtained from the Institute research council and Ethics committee.

200 patients in active labour who were admitted in labour room irrespective of their parity were selected randomly for the study.

\section{Inclusion Criteria}

- Women with term gestation irrespective of parity

- Singleton pregnancies

- Live baby

- Spontaneous onset of labour

- Women in active labour.

- Cephalic presentation

Exclusion Criteria

- Twin gestation

- Preterm delivery

- Intrauterine death 


\section{International Journal of Science and Research (IJSR) \\ ISSN (Online): 2319-7064 \\ Index Copernicus Value (2013): 6.14 | Impact Factor (2015): 6.391}

- Anomalous baby

- Malpresentation

- Pre eclampsia

- Elective caesarian sections.

200 patients who were in active labour with term gestations, irrespective of parity, with singleton pregnancies with live babies and were admitted in labour room were included in the study . Patients were observed in second and third stage of labour. After separating the baby from umbilical cord, the cord was clamped and cut close to the baby as possible. The umbilical cord was measured including both the placental end of the cord and umbilical stump on the baby side. Number of complete coils or spirals was counted.

After this UCI was calculated by dividing total number of coils by the total length of the cord in centimeters.

\section{UCI = numbr of coils/ total length of the cord}

Then, perinatal parameters like birth weight, meconium staining, gender, NICU admission, Apgar score at 1 minute, Apgar score at 5 minutes, fetal growth restriction, direction of twist were correlated with umbilical coiling index.

Thus the effect of umbilical vascular coiling and perinatal outcome was studied. All the mothers and babies were followed up till discharge.

\section{Statistical Analysis}

- Data was entered in Microsoft excel and analysis was done using SPSS version 20.

- Prospective statistical analysis was done. Results are presented as numbers and percentages.

- Chi square test is used to find out the significance of study parameters on a categorical scale between two groups.

- P value : Significance is assessed at $5 \%$ level of significance.

\section{Results}

Table 1: Birth weight

\begin{tabular}{|c|cc|c|c|}
\hline Baby details & \multicolumn{2}{|c|}{ criteria } & Number of neonates & $\%$ \\
\hline \multirow{3}{*}{ Birth weight } & $<2.5$ & 26 & $13 \%$ \\
\cline { 2 - 4 } & 2.5 & -3.5 & 168 & $84 \%$ \\
\cline { 2 - 4 } & $>3.5$ & 6 & $3 \%$ \\
\hline Total & & 2 & $100 \%$ \\
\hline
\end{tabular}

The number of babies with birth weight $<2.5 \mathrm{~kg}$ are 26 (13\%), between $2.5-3.5 \mathrm{kgs}$ are $168(84 \%)$ and $>3.5$ are $6(3 \%)$.

Table 2: Apgar score at 1 minute

\begin{tabular}{|c|c|c|c|}
\hline Baby details & criteria & Number of neonates & $\%$ \\
\hline Apgar score at $1 \mathrm{~min}$ & $<4$ & 43 & $21.5 \%$ \\
\cline { 2 - 4 } & $>4$ & 157 & $78.5 \%$ \\
\hline total & & 200 & $100 \%$ \\
\hline
\end{tabular}

Babies born with Apgar score at 1 minute $<4$ were 43 (21.5\%) and $>4$ were 157 (78.5\%).
Table 3: Apgar score at 5 minutes

\begin{tabular}{|c|c|c|c|}
\hline Baby details & criteria & Number of neonates & $\%$ \\
\hline $\begin{array}{c}\text { Apgar score at } 5 \\
\text { min }\end{array}$ & $<7$ & 25 & $12.5 \%$ \\
\cline { 2 - 4 } & $>7$ & 175 & $87.5 \%$ \\
\hline total & & 200 & $100 \%$ \\
\hline
\end{tabular}

Babies born with Apgar score at 5 minutes $<7$ were 25 (12.5\%) and > 7 were 175 (87.5\%).

Out of 200 babies, 35 (17.5\%) were admitted in NICU and the rest $165(82.5 \%)$ were not admitted.

Table 4: NICU admissions

\begin{tabular}{|c|c|c|c|}
\hline Baby details & Criteria & Number of neonates & $\%$ \\
\hline NICU admissions & Yes & 35 & $17.5 \%$ \\
\hline & no & 165 & $82.5 \%$ \\
\hline total & & 200 & $100 \%$ \\
\hline
\end{tabular}

Table 5: fetal distress

\begin{tabular}{|l|l|l|l|}
\hline Baby details & criteria & Number of neonates & $\%$ \\
\hline \multirow{2}{*}{ Fetal distress } & Yes & 52 & $26 \%$ \\
\cline { 2 - 4 } & no & 148 & $74 \%$ \\
\hline total & & 200 & $100 \%$ \\
\hline
\end{tabular}

Out of 200 babies in the study, 52 (26\%) had fetal distress and the rest 148 (74\%) had no fetal distress.

Table 6: Meconium staining

\begin{tabular}{|c|c|c|c|}
\hline & Criteria & Number of Neonates & $\%$ \\
\hline Meconium & Yes & 42 & $21 \%$ \\
\cline { 2 - 4 } Staining & NO & 158 & $79 \%$ \\
\hline Total & & 200 & $100 \%$ \\
\hline
\end{tabular}

The meconium stained liquor was found in 42 cases (21\%) and clear liquor is seen in 158(79\%) . any concentration of liquor was taken into the criteria (thin or thick).

\section{Discussion}

Several studies in the past have correlated the relationship between perinatal outcome and the UCI The umbilical coiling index has found to be an effective indicator of perinatal outcome.

This is a prospective study over a time period of 2 YEARS from conducted in the department of obstetrics and gynaecology, Modern Government Maternity Hospital, Osmania medical college, Hyderabad aimed to correlate the importance of patterns of umbilical coiling in terms of umbilical coiling index with various fetal parameters.

Women as per the selection criteria were taken for the study UCI was calculated by strong et al formula, dividing the total number of coils by the total length of the cord in centimeters and the UCI obtained was correlated with the various parameters. The UCI was correlated to the birth weight, Apgar score at $1 \mathrm{~min}$ and $5 \mathrm{~min}$, NICU admissions, meconium staining, fetal distress, fetal growth restriction.

The mean length of the umbilical cord in the study was 52.87 +/- 13.49. The mean number of coils was $12.59+/$ 5.38 . 


\section{International Journal of Science and Research (IJSR) \\ ISSN (Online): 2319-7064 \\ Index Copernicus Value (2013): 6.14 | Impact Factor (2015): 6.391}

The mean UCI in the study is comparable to the study done by Ezimokhai et al (2001) and Chitra et al (2012).

In consideration of the abnormal versus normal coiling distribution in this study, it was observed that $10^{\text {th }}$ percentile - hypocoiling (UCI $<0.06$ ) and $90^{\text {th }}$ percentile hypercoiling (UCI >0.41) were in agreement with the previous studies. Among the 200 patients, out of which 159 (79.5\%) had normocoiling i.e., UCI between $10^{\text {th }}$ to $90^{\text {th }}$ percentile. 23 cases $(11.5 \%)$ had hypocoiling i.e., UCI $<10^{\text {th }}$ percentile, $18(9 \%)$ cases had hypercoiling, i.e., UCI $>90^{\text {th }}$ percentile.

The women included in the present study were in the age group ranging from 18- 35 years .Majority of the women in the age group 20 - 27 years. Total number of mothers in the age group between 18 - 34 were 197(98.5\%) . among which $22(11.16 \%)$ had hypocoiled cords, 157(79.69\%) had normocoiled cords and 18(9.14\%) had hypercoiled cords.3(1.5\%) were in the age group of $>/$ - 35 years, among which $1(33.33 \%)$ had hypocoiling and the rest $2(66.66 \%)$ had normocoiled cords. $\mathrm{P}$ value for hypocoiled cords was found to be 0.28 and hypercoiled cords was 0.63 .there is no statistical significance between these two groups.

Ezimokhai et al. found hypercoiling to be associated with extremes of maternal age $(<20$ and $>35$ years). None of the other studies found age to be a significant factor.

UCI was correlated with birth weights of the newborn $26(13 \%)$ had birth weights $<2.5 \mathrm{kgs}$, out of which $13(50 \%)$ had normocoiling, 12(46.15\%) had hypercoiling and 1(3.84\%) had hypocoiling. 168 (84\%) babies had birth weights between 2.5 - $3.5 \mathrm{kgs}$. Of which $141(83.92 \%)$ had normocoiled cords, 21(12.5\%) had hypocoiling and 6(3.57\%) had hypercoiled cords. 6 (3\%) had birth weights $>3.5 \mathrm{kgs}$, of which 5(83.33\%) had normocoiled and $1(16.66 \%)$ had hypocoiling. $P$ value being $<0.01$ is strongly significant. Literature has found a consistent association between hypercoiled and LBW babies, as shown by Rana et . al., Raio et . al and de Laat et. al .However the authors were unable to give a satisfactory explanation for this association. 43(21.5\%) babies had Apgar at 1 min < 4, out of them 32 (74.4\%) had normocoiling, 10 (23.2\%) had hypocoiling and 1 (2.4\%) had hypercoiling. 157 (78.5\%) babies had Apgar at 1 minute $>4$, out of them $127(80.3 \%)$ had normocoiling, 13 (8.9\%) had hypocoiling and 17(10.8\%) had hypercoiling · p value being 0.02 for hypocoiled cords and 0.13 for hypercoiled cords is strongly significant suggestive of correlation between the two groups. hypocoiled cords more associated than hypercoiled cords. .Gupta S et. al studies 107 umbilical cords and found that in hypocoiled cords, low apgar scores were present . in another study which was done by Padmanabhan et . al 130 umbilical cords were studied and it was found that in hypocoiled groups, there were significantly low Apgar scores.

25(12.5\%) babies had Apgar at $5 \mathrm{~min}<7$, out of them 17(68\%) had normocoiling, 6 (24\%) had hypocoiling and 2 (8\%) had hypercoiling. 175 (87.5\%) babies had Apgar at 5 minutes $>7$, out of them 142 (81.14\%) had normocoiling, 17 (9.71\%) had hypocoiling and 16 (9.14\%) had hypercoiling . $\mathrm{p}$ value being for hypocoiled cords 0.002 and for hypercoiled cords 0.97 . the p value of hypocoiled cords is strongly suggestive of significant correlation between the two groups. hypocoid cords are associate with low apgar at 7 minutes.

35(17.5\%) babies out of 200 babies were required NICU care, out of them 19 (54.28 \%) had normocoiling, 10 (28.57\%) had hypocoiling and 6 (17.14 \%) had hypercoiling. 165(82.5\%) babied did not require any NICU care, out of them 140(84.84\%) had normocoiling, 13 (7.87 \%) had hypocoiling and 12(7.27 \%) had hypercoiling . p value being 0.001 for hypocoiled cords and 0.0136 for hypercoiled cords is strongly significant suggestive of correlation between the two groups. hypocoiled cords more associated than hypercoiled cords.

Out of 200 babies, 23(11.5\%) had fetal growth restriction. Out of which 2(8.69 \%) had hypocoiling, 8 (34.78\%) had normocoiling and 13(56.52 \%) had hypercoiled cords. Rest $177(88.5 \%)$ had no fetal growth restriction, of which, 21(11.86\%) had hypocoiled cords, 151(85.31 \%) had normocoiled cords and 5(2.82 \%) had hypercoiled cords. p value being 0.51 for hypocoiled cords and $<0.001$ for hypercoiled cords, suggests strong significance between hypercoiled cords and fetal growth restriction.

Out of 200 babies, 52 (26\%) had fetal distress. Out of which 17(32.69 \%) had hypocoiling, 28 (53.84\%) had normocoiling and 7(13.46 \%) had hypercoiled cords. Rest 148 (74 \%) had no fetal distress, of which, 6(4\%) had hypocoiled cords, 131(88.5\%) had normocoiled cords and $11(7.43 \%)$ had hypercoiled cords. p value being $<0.01$ for hypocoiled cords and 0.032 for hypercoiled cords, suggests strong significance between two groups. hypocoiled is more associated thatn hypercoiled cords .Rana et al. and Ercal et al. found FHR decelerations to be significantly associated with hypocoiled cords. Rana et al. explained that coiling provides turgor and compression resistant properties to the cord which become compromised as the cord becomes hypocoiled.

Out of 200 cases studied, 42(21\%) had meconium stained liquor out of which, 14(33.33\%) had hypocoiled cords, 22(52.38\%) had normocoiled cords and 6(14.28\%) had hypocoiled cords. 158(79\%) did not have any meconium staining of the liquor. Out of them, 9(5.69\%) had hypocoiled cords, $137(86.7 \%)$ had normocoiled cords and $12(7.59 \%)$ had hypercoiled cords .Meconium staning of the amniotic fluid was found to be significantly associated with both hypocoiled ( $p$ value $=<0.01)$ and hypercoiled $(p$ value $=$ 0.03) cords . . Gupta $S$ et . al studied 107 umblical cords and found that in hypocoiled groups meconium staining of the liquor was significantly higher than in those with normocoiled group. Strong et al. studied 100 cases and they found that the meconium staining was associated with UCI values $<10^{\text {th }}$ percentile, with $\mathrm{p}$ value 0.03 which was highly significant. in another study which was done by Padmanabhan LD et . al 130 cases were studied, which they found that the meconium staining was significant in hypercoiled group.

\section{Volume 5 Issue 4, April 2016




\section{International Journal of Science and Research (IJSR) \\ ISSN (Online): 2319-7064 \\ Index Copernicus Value (2013): 6.14 | Impact Factor (2015): 6.391}

\section{Conclusion}

$\mathrm{UCI}<10^{\text {th }}$ percentile $<0.06$

UCI $>90^{\text {th }}$ percentile $>0.41$

The mean length of the umbilical cord in the study was $\mathbf{5 2 . 8 7}+/$ - 13.49 .

The mean number of coils was $\mathbf{1 2 . 5 9}+/-\mathbf{5 . 3 8}$

The mean umbilical coiling index (UCI) was $0.24+/-0.09$ which is consistent with the previous studies.

The UCI was correlated to the maternal factors like maternal age, birth weight, APGAR score at $1 \mathrm{~min}$ and $5 \mathrm{~min}$, NICU admissions, meconium staining, fetal distress, fetal growth restriction, direction of twist of the cord.

HYPOCOILING (UCI $<10^{\text {th }}$ percentile) is associated with low birth weights, low APGAR score at 1 minute of the baby, low APGAR scores at 5 minutes, more NICU admissions, fetal distress associated with the baby and also meconium staining of the liquor.

HYPERCOILING (UCI $>90^{\text {th }}$ percentile) is associated with low birth weights, low APGAR score at 1 minute, NICU admissions, and fetal growth restriction. It is also associated with fetal distress of the baby and also meconium staining of the liquor.

Thus antenatal detection of the coiling index can identify fetus at risk and thus help in further management and timely intervention.

\section{Summary}

The umbilical cord is vital for development, wellbeing and survival of the fetus and yet, it is vulnerable to kinking, compressions, traction and torsion which may affect the perinatal outcome. The total number of coils for any particular cord is believed to be established early in gestation. The pattern of coiling develops during second and third trimesters, presumably due to smashes in the cord and these coiling changes as the pregnancy advances. The three blood vessels pass along the length of the cord in helical or coiled fashions. The helical fashion of these umbilical vessels is termed as spiral course

The vessels of the cord like all hollow cylinders are prone to torsion, compression, tension, and subsequent interruption of the blood flow. This risk is minimized by their helical disposition. The coiled umbilical cord perhaps of its elastic properties, is able to resist external forces that might compromise the umbilical vascular flow the coiled umbilical cord acts like a semi erectile organ that is more resistant to snarling, torsion, stretch and compression than noncoiled cord. This is referred to as "spontaneous internal ballotment" .Regardless of its origin, umbilical coiling appears to confer turgor to the umbilical unit, producing the cord that is strong but flexible.

This is a prospective study with 200 cases carried out to calculate the UCI and correlate the relationship between the abdominal umbilical coiling index (hypo or hyper) and adverse perinatal outcome.
Baseline characters were similar in the three groups .There was a significant difference between the hypercoiled and hypocoiled group with respect to the perinatal parameters like FGR, meconium staining, low APGAR score at $1 \mathrm{~min}$ and 5 minutes and birth weights.

Thus both hypo and hypercoiling of cords had significant correlation with adverse fetal outcome. The findings of the present study point out that low UCI is an indicator of perinatal complications. Antenatal detection of this abnormal coiling index by ultrasound can lead to identification of fetus at risk. The sensitivity values of antenatal sonography to predict hypocoiling and hypercoiling were $78.9 \%$ and $25.4 \%$ respectively .Thus quatitatIng the degree of umbilical vascular coiling can be significant with proper correction in the antepartum period.

\section{References}

[1] Gupta S, Faridi MMA, Krishnan J. Umbilical coiling index. The Journal of Obstetrics \& Gynecology of India. 2006; 56(4):315-319.

[2] Rana J, Ebert GA, Kappy KA. Adverse perinatal outcome in patients with an abnormal umbilical coiling index. Obstetrics and Gynecology. 199585(4):573-577.

[3] Edmonds HW. The spiral twist of the normal umbilical cord in twins and in singletons. American Journal of Obstetrics and Gynecology. 1954;67(1):102-120.

[4] Strong TH, Jarles DL, Vega JS, Feldman DB. The umbilical coiling index. American Journal of Obstetrics and Gynecology. 1994;170(1, part 1):29-32.

[5] Lacro RV, Jones KL, Benirschke K. The umbilical cord twist: origin, direction, and relevance. American Journal of Obstetrics and Gynecology. 1987;157(4):833-838

[6] Strong TH, Finberg HL, Mattox JH. Antepartum diagnosis of noncoiled umbilical cords. Am J. Obstet Gynecol. 1994;170:1729-33

[7] Ercal T, Laun S, Altunyurt S, Saygili U, Cinar O, Mumcu A. Umbilical coiling index: is it a marker for fetus at risk? The British Journal of Clinical Practice. 1996;50(5):254-256.

[8] Cunningham FG, Gant NF, Leveno KJ, Gilstra III LC, Hauth JC, Westrom KD.The placenta and fetal membranes in ; textbook of Williams $21^{\text {st }}$ edition. New York :Mc graw hill ;2001: 105-106

[9] Stephen A .Heifetz . The umbilical cord : Obstetrically important lesions, clinical Obstetrics and Gynaecology $1996 ; 39: 571$ - 87.

[10] Dutta D.C ., the placenta and fetal membrane ; textbook of obstetrics . $6^{\text {th }}$ edn, Calcutta, new central book agency private limited ;2004:28-40

[11] M. W. M. De Laat, A. Franx, M. L. Bots, G. H. A. Visser, and P. G. J. Nikkels, "Umbilical coiling index in normal and complicated pregnancies, " Obstetrics and Gynecology, ;2006: 107 (5):1049-1055

[12] Georgiou HM, Rice GE, Walker SP, Wein P, Gude NM, Permezel M. The effect of vascular coiling on venous perfusion during experimental umbilical cord encirclement. Am J Obstet Gynecol, 2001;184(4):673678.

[13]Fox H. pathology of placenta .philadelphia .WB saunders 1970 


\section{International Journal of Science and Research (IJSR) \\ ISSN (Online): 2319-7064 \\ Index Copernicus Value (2013): 6.14 | Impact Factor (2015): 6.391}

[14] Naeye RL. Disorders of the placenta . fetus and neonate : diagnosis and clinical significance st.louis mosby year book, 1992

[15] Hankins G.D ., Synder RR, Hauth JC, Gilstrap LC $3^{\text {rd }}$, Hammond $\mathrm{T}$.Nuchal cords and neonatal outcome .Obstet gynecol 1987 ; 70 :687 - 91

[16] Jauniaux E, Ramsay B, Peellaerts C, Scholler Y . Perinatal features of pregnancies complicated by nature cord . Am J . perinatal $1995 ; 12$ : 225 -28

[17] Malpas P, Symonds EM. Observations on the structure of the human umbilical cord. Surg Gynecol Obstet 1966;123:746-750

[18] Roach MR . the umbilical vessels . in : Evans HE, glass L, edts, Perinatal medicine . $13^{\text {th }}$ edn . Hagerstown MD : Harper and Row : 1976 ; 134 -42

[19] Cullen TS. Embryology, Anatomy and Diseases of the Umbilicus, together with Disease of the Urachus. Illustrations by Max Bro“ del. Philadelphia, and London: WB Saunders Co;1916.

[20] Chaurasia BD, Agarwal BM. Helical structure of the human umbilical cord. Acta Anatomica. 1979;103(2):226-230.

[21] Benirschke K, Kaufmann P. Pathology of the human placenta. New York: Springer; 1995.

[22] Degani S, Reuven M, Lewinsky, Berger H, Spiegel D .Sonographic estimation of umbilical coiling index and correlation with Doppler flow characteristics .Obstet gynecol 1995 ;86 (4) : 990- 93

[23] Politzer G, Sternberg SH, Uberdie entwicklung der ventralen korperwand unddes nabelstranges being menschen Z. gen . anat 1930 ; 92 : 279 - 379

[24] Blickstein I, Varon E . Implications of the difference in coiling indices at different segments of umbilical cord . Gynecol obstet invest $2001 ; 52: 203-06$

[25] Machin GA, Ackermann J, Gilbert- Barness E. Abnormal umbilical cord coiling is associated with adverse perinatal outcomes. Pediatric and Developmental Pathology. 2000;3(5):462-471

[26] Sibulkin M.A note on the bath tub vortex theory and the earth s rotation.Am Sci 1983 ; 71 :352-53.

[27] Corballis MC, Morgan MJ . On the biological basis of human laterality : evidence for a maturational left right gradient. II the mechanisms of inheritance. behav brain sci $1978 ; 2: 261$ - 336.

[28] Pande BS, Sungh I . One sided dominances in the upper limbs of human fetuses as evidence by asymmetry in muscle and bone. J Anat 1971 ; 109 : 457 -59.

[29]K lopper A. Diezfalusy E. fetus and placenta (Blackwell, oxford 1969)

[30] Brews . Holland and brew's manual of obstetrics $.12^{\text {th }}$ edition . London :Churchill ;1963

[31] Johnstone RW, Keller RJ . A textbook of midwifery for students and practitioners. $19^{\text {th }}$ edn. London : Adams and Black :1963

[32] Masani KM, Parikh MN . A textbook of obstetrics . $2^{\text {nd }}$ edn . Bombay :popular prakashan :1969.

[33] Strong Jr. TH, Elliott JP, Radin TG. Non-coiled umbilical blood vessels: a new marker for the fetus at risk. Obstetrics and Gynecology. 1993;81(3):409-411.

[34] Ezimokhai M, Rizk DEE, Thomas L. Maternal risk factors for abnormal vascular coiling of the umbilical cord. American Journal of Perinatology. 2000;17(8):441-446.
[35] Pudmanabhan LD, Mhaskar R, Mhaskar A . umbilical vascular coiling and the perinatal outcome .J Obstet And Gynecol India 2001; 51 (6) :43- 44

[36] Predanic M, Perni SC, Chasen ST et al. Assessment of umbilical cord coiling during the routine fetal sonographic anatomic survey in the second trimester . J Ultrasound Med 2005;24: 185-91

[37] Y.Qin, T.K. Lau and M.S.Rogers.second trimester ultrasonographic assessment of the umbilical coiling index, Ultrasound obstetrics and gynaecology 2002 ;20:458-463

[38] Raio L, Ghezzi F, Di Naro E, et al. Prenatal diagnosis of a lean umbilical cord: a simple marker of the fetuses at risk. Ultrasound in Obstetrics \& Gynecology. 1999;13(3):157-160.

[39] Dr J. Nishio, Y. Nakai, M. Mine, M. Imanaka and S. Ogita Characteristics of blood flow in intrauterine growth-restricted fetuses with hypercoiled cord, ultrasound Obstet gynecol 1999 ; 13 :171 - 175

[40]Dakshayini devaru and Meghna thusoo . umbilical coiling index and perinatal outcome .J obst and gynaec India, 2012;62(1):43 - 46

[41] T.Chitra . Y.S Sushanth, S.Raghavan, umbilical coiling index as a marker of perinatal outcome :an analytical study, obst and gynecol. 2012

[42] Jo YS, Jang DK, Lee G . the sonographic umbilical cord coiling in late second trimester of gestation and perinatal outcomes: Int J Med Sci 2011;8(7) :594 -98

[43] Dw Laat MW, Franx A, Nikkels PG, Visser GH .prenatal ultrasonographic prediction of the umbilical coiling index at birth and adverse perinatal outcome, 2006:28(5) :704 -09

[44] Degani S ${ }^{1}$, Leibovich Z, Shapiro I, Gonen R, Ohel G. Early second-trimester low umbilical coiling index predicts small-for-gestational-age fetuses. J Ultrasound Med. 2001 Nov;20(11):1183-8.

[45] Bruch $\mathrm{JF}^{1}$, Sibony O, Benali K, Challier JC, Blot P, Nessmann C. Computerized microscope morphometry of umbilical vessels from pregnancies with intrauterine growth retardation and abnormal umbilical artery Doppler. Hum Pathol. 1997 Oct;28(10):1139-45.

[46] Jeannine Gebrane-Younes, Hoang Ngoc Minh, Louis Orcel $^{\mathrm{a}}$ Ultrastructure of human umbilical vessels: a possible role in amniotic fluid formation? Placenta 986 ; $7: 173-185$

[47]Bernard Rosner Fundamentals of Biostatistics, 5th Edition, dexbury, page 80- 240

[48] M.venkataswamy reddy, statistics for mental health care research, NIMHANS publication, INDIA, 2002 : 108 144

[49] Sunder Rao P S S, Richard J : an introduction to biostatistics, a manual for students in health sciences, New Delhi :prentice hall of India, 86-160

[50]Eng J. Sample size estimation: how many individuals should be studied? Radiology 2003; 227: 309-313 